then. Percentages of fat in the women students varied from $23 \cdot 0 \%$ to $32 \cdot 2 \%$ when calculated from circumferences and were comparable $(21.6 \%$ to $31.5 \%)$ when calculated from skin fold measurements.

\section{Comment}

Our results show that display figures have become thinner with time and their proportions now differ considerably from those of normal young women. The structural changes seen in display figures during this century have led to a considerable reduction in the proportion of body weight calculated to be fat. A woman with the shape of a modern mannequin would probably not menstruate.

We often take a smiling or even horrified attitude towards the fashion phenomena of foreign cultures, but in our own society we get accustomed to the whims of fashion from early childhood. A woman with the proportions of a Barbie doll would be even thinner than the modern display figure (unpublished observations). Many of the phenomena of fashion are harmless, but the trend of extreme thinness is not without dangers. Most girls in industrialised countries are concerned with their body shape and practise occasional dieting. ${ }^{5}$
Although most of them survive without major problems, persistent dissatisfaction with one's own body may cause unnecessary concern and lessen happiness. In some girls this may proceed to the development of an eating disorder.

Why is the idealised weight so low? From the history of fashion we can see that during times of scarcity wide skirts with plenty of material were fashionable. When plenty of material was available the skirts were short and narrow. Similarly, being fat was socially desirable in times when there was a shortage of food. Now, in societies with excess food the ideal body shape is extremely thin. It seems that things difficult to achieve are pursued.

1 Frisch RE. Fatness, menarche and female fertility. Perspect Biol Med 1985;28:611-33.

Steinkamp RC, Cohen NL, Gaffey WR, McKey T, Bron G, Siri WE, et al. Measures of body fat and related factors in normal adults. II. A simple clinical method to estimate body fat and lean body mass. F Chron Dis 1965;18: 1291-307

Scott EC, Johnston FE. Critical fat, menarche, and the maintenance of menstrual cycles. F Adolesc Health Care 1982;2:249-60.

Smith DP, Boyce RW. Prediction of body density and lean body weight in females 25 to 37 years old. Am 7 Clin Nutr 1977;30:560-4

5 Patton GC, Johnson-Sabine E, Wood K, Mann AH, Wakeling A. Abnormal eating attitudes in London schoolgirls - a prospective epidemiological study: outcome at twelve months. Psychol Med 1990;20:383-94.

\title{
How to gain weight by looking up
}

\section{A J Newens, S N Jarvis, R George}

Low birth weight is generally defined as births "less than $2500 \mathrm{~g}$ (up to and including $2499 \mathrm{~g}$ )" and is associated with increased perinatal mortality risk. ${ }^{2}$ An alternative criterion for low birth weight (less than $2800 \mathrm{~g}$ ) was used by Townsend $e t a l$ as part of a health index for districts in the Northern health region of England.

During a study of perinatal mortality in Gateshead we examined the recording of birth weight over time to explain a fall from $7 \cdot 8 \%$ in 1982 to $5 \cdot 9 \%$ (below the average in Northern region) in 1990 in the proportion of babies weighing less than $2500 \mathrm{~g}$ at birth. There was less change $(14 \cdot 8-14 \cdot 1 \%)$ when $2800 \mathrm{~g}$ was used as a criterion.

\section{Method and results}

Data on the weight of babies born to mothers resident in Gateshead were obtained from the Office of Population Censuses and Surveys for the years 1982-

BMF 1992;305:1576-7

Weights recorded on birth certificates

No of births recorded by year

\begin{tabular}{|c|c|c|c|c|c|c|c|c|c|c|c|}
\hline $\begin{array}{l}\text { Weight } \\
\text { (grams) }\end{array}$ & 1982 & 1983 & 1984 & 1985 & 1986 & 1987 & 1988 & 1989 & 1990 & 1991 & Total \\
\hline 2780 & 22 & 21 & 18 & 26 & 22 & 11 & 22 & 23 & 27 & 23 & 215 \\
\hline 2785 & & 1 & & 1 & & & & & & & 2 \\
\hline 2788 & & & 1 & & & & & & & & 1 \\
\hline 2790 & 2 & 5 & 3 & & 1 & & & 1 & 1 & & 13 \\
\hline 2792 & & & & & 1 & & & & & & 1 \\
\hline 2795 & 1 & & & 2 & & & & & & & 3 \\
\hline 2800 & 22 & 20 & 15 & 2 & 1 & 4 & 8 & 5 & 1 & 1 & 79 \\
\hline 2805 & & 1 & & 1 & 1 & & & & & & 3 \\
\hline 2807 & 3 & l & 1 & & 1 & 1 & 1 & 1 & 2 & & 11 \\
\hline 2810 & 3 & $i$ & 11 & 25 & 24 & 21 & 16 & 21 & 24 & 20 & 166 \\
\hline 2815 & 2 & & & & & 1 & & & & 1 & 4 \\
\hline 2820 & 23 & 15 & 20 & 2 & 1 & 3 & 4 & 3 & 2 & 2 & 75 \\
\hline 2824 & & & 1 & & & & & & & & 1 \\
\hline 2825 & & 1 & 1 & & & & & & 1 & 1 & 4 \\
\hline 2826 & & $i$ & & & & & & & & & i \\
\hline 2830 & 1 & & 1 & 2 & 1 & 1 & 1 & 1 & 1 & 3 & 12 \\
\hline 2835 & 4 & 3 & 3 & 4 & 2 & 3 & 2 & 1 & 3 & 6 & 31 \\
\hline 2840 & 2 & 4 & 8 & 43 & 16 & 26 & 31 & 35 & 22 & 20 & 207 \\
\hline 2845 & & & & & & 1 & & 1 & & & 2 \\
\hline
\end{tabular}

These data were derived from birth notification documents completed at the time of birth, in grams, by a midwife and subsequently transferred to the registrar of births. In the Gateshead maternity unit, which accounted for two thirds of local births, the babies were weighed on the same analogue scales calibrated in $20 \mathrm{~g}$ and 1 ounce intervals throughout the study period. In the two Newcastle hospitals that deliver most other Gateshead babies both analogue and digital scales were used. Of the 26131 birth registrations, $0 \cdot 3 \%$ had birth weight missing.

Rounding of most weights, in $20 \mathrm{~g}$ or $30 \mathrm{~g}$ increments, was found throughout the study period. The pattern of rounding changed, however, over the period 1983 to 1985 , and there was a tendency for weights to be $10 \mathrm{~g}$ or $20 \mathrm{~g}$ higher after 1985 . As an example, the distribution of birth weights between $2770 \mathrm{~g}$ and $2850 \mathrm{~g}$ is shown in the table. The weight $2780 \mathrm{~g}$ remained over the study period, whereas $2800 \mathrm{~g}$ increased by $10 \mathrm{~g}$ to $2810 \mathrm{~g}$, and $2820 \mathrm{~g}$ increased by $20 \mathrm{~g}$ to $2840 \mathrm{~g}$. Although rounding was noted in at least two hospitals, individual maternity units were identifiable only from 1989 onwards.

Although it was not as clear cut as at higher birth weights, a degree of readjustment was apparent at $2500 \mathrm{~g}$. In 1982-3 six births were recorded at exactly this weight, whereas in 1985-6 the number was 18 . By 1989-90 the number had risen further to 30 .

\section{Discussion}

Any cut off point for the definition of low birth weight calls for accurate recording of such information if useful comparisons are to be made between districts. The increase in the number of babies recorded as weighing exactly $2500 \mathrm{~g}$ after $1982-3$, although small in comparison to the overall number of births, may nevertheless account for a part of the apparent fall in the proportion of low birthweight babies born to Gateshead mothers. As there was no upward revision 


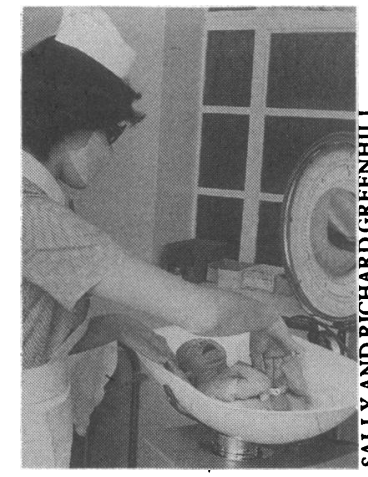

Converting 5 lb 8 oz to $2480 \mathrm{~g}$ or $2500 \mathrm{~g}$. It makes a difference, statistically of weights to exactly $2800 \mathrm{~g}$ this is consistent with the finding that there was less change in the proportion of low birthweight babies when this was used as the cut point. The change in recording suggests that a new look up table was introduced at some point for conversion of imperial to SI units (note that 1 ounce= 28 grams).

Mothers are usually familiar with, and prefer, pounds and ounces rather than grams, whereas official recording is undertaken in grams. If analogue scales are used dual reading of weight may be difficult, and the use of a look up table for conversion to SI units may offer a ready solution. If weight is rounded twice, first in ounces and then with a look up table when converting to grams, inaccuracies of up to almost $30 \mathrm{~g}$ may occur regularly.

Digital readout scales incorporating a printout and memory function may offer a solution but may not be an expense considered worthwhile by maternity units on clinical grounds. Until such devices are standard, rigorous adoption of SI units with regard to birth weight may require further encouragement within some maternity units.

Thanks are due to Miss Morley, director of midwifery, Queen Elizabeth Hospital, Gateshead, and Mr A McNay, statistician, Northern Health Region, for help with information.

1 World Health Organisation. Manual of International Statistical Classification of Diseases, Injuries and Causes of Death. Vol 1. Geneva: WHO, 1977.

2 Barell V, Wax Y, Ruder A. Analysis of geographic differentials in infant mortality rates. Am $\mathcal{F}$ Epidemiol 1988;128:218-30.

3 Townsend P, Phillimore P, Beattie A. Health and deprivation inequality and the north. Beckenham: Croom Helm, 1988.

\section{An unusual case of neuropathic ulceration}

\section{Keith Tayton}

The case described is of severe ulceration of the soles of both feet as a result of a transient but total anaesthesia in both legs.

\section{Case report}

A 58 year old man from a mining village in Gwent travelled to Yorkshire to attend a rugby match in the autumn of 1985. After the game he adjourned to a series of local taverns. By closing time he found himself many whiskies and over 12 pints of beer in credit, but he was 250 miles from home and had no money. Being, by now, a man of some spirit, he resolved to walk back to Gwent and purposefully headed south. Before he had gone far, his feet began to feel very sore owing to loosening of his shoes. To him there seemed only one solution, so he removed the offending shoes and threw them over a nearby hedge before continuing his journey. He tramped on, taking short cuts over walls and fences, sustaining a moderately severe head injury at one stage. Many miles later, near Barnsley, he flagged down a taxi and fell into the back seat, asking to be taken home.

About four hours later the patient's wife was summoned from her bed and presented with a taxi bill

Royal Gwent Hospital, Newport, Gwent NP9 2UB Keith Tayton, consultant orthopaedic surgeon

BMF 1992;305:1577

Four days after admission to hospital the sole of the right foot still showed full thickness skin loss; exposed tendons were beginning to granulate over for $£ 115$. There was an initial danger of the patient spending the remainder of the weekend in his garden shed, but when this crisis had passed he retired to bed. Several hours later he appeared in the accident and emergency department in great pain and with severely ulcerated feet.

The left foot had full thickness skin loss under the second and third metatarsal heads and a partial thickness skin loss under the fourth and fifth metatarsal heads, under the tip of the big toe, and under the heel. The right foot had a severely contaminated wound under the second and third metatarsal heads. It consisted of a full thickness loss of the skin and subcutaneous fat, with exposure of the flexor tendons of the second and third toes. Partial thickness skin loss was also present under the first, fourth, and fifth metatarsal heads, under the tip of the big toe, and under the heel (figure).

All wounds underwent debridement and were cleaned and dressed. They healed without important complications over six weeks. No evidence of peripheal neuropathy could be found.

\section{Comment}

Well over half of the world's people always walk barefoot, but although terrain can vary considerably, severe ulceration of the foot is not often seen. It is well known that when long distance walking is undertaken by the uninitiated then blistering of the skin will develop, especially if shoes are worn. The extent of this blistering is limited usually by the severe pain experienced by the sufferers at the time.

Anaesthetic feet due to peripheral neuropathies are common and may present with ulceration much more severe than in this patient. This case is unusual, however, in that the anaesthesia was transient and almost total. Although the alcohol consumption was so great that its effect lasted for several hours, motor power and a reasonable amount of coordination were retained to such a degree that the patient was able to walk right through the soles of his feet and expose the flexor tendons to two of his toes.

As a result of this experience both the author and the patient would strongly recommend that before the results of any sporting fixture are celebrated, both shoes should be well fitting and firmly attached to the feet. 